Independent Review team to discuss action taken since the review was published and reflect on its relevance now, and what further work remains to be done.

Perhaps the most interesting information to emerge from the session was the progression and stagnation brought about by the General Election in 2010 and what they expected post 2015. In 2010 the review's recommendations were put on hold almost 12 months after their findings were presented. With a level of continuity in Government after the latest election, the panel were cautiously optimistic of further progress towards implementing key recommendations made in the Steele Report.

Well, why worry? ...you don't get pregnant with oral sex!

It may sound frivolous to many, but oral sex is a very real problem. Val McMunn explained how current evidence shows adolescents view oral sex as less risky compared to genital sex, which has led to a sharp rise in the number of HPV-related oral cancer cases both in the UK and worldwide.

When Michael Douglas declared that his oral cancer was caused by HPV, it was only then people started to take the topic seriously. There are many strains of the HPV virus, and HPV-16 and -18 are the strains the profession should be most concerned about. With oral sex on the increase, no realistic preventive message and a stigma attached to sexually transmitted diseases - of which HPV is one - Val warned the profession will be challenged with detecting HPV cases as they increase.

The problem is further complicated by the late presentation of symptoms. Val explained how, if caught at stage one or two, survival rates can be as high as 90 percent. Without that, rates are much lower. Delays in diagnosis cost lives, and she urged people to get involved with campaigns such as Mouth Cancer Action Month. Educating and screening patients on the risk factors is a key job, with any potential signs and symptoms reported and acted upon immediately.

\title{
LEADING HEALTHCARE PROFESSIONALS CALL FOR SAFER DELIVERY OF SEDATION FOR DENTAL PATIENTS
}

The Intercollegiate Advisory

Committee for Sedation in Dentistry has launched new national standards to ensure the safe, high quality delivery of conscious sedation for dental patients.

The report: Standards for conscious sedation in the provision of dental care, highlights the need to ensure the quality of care delivered to dental patients requiring conscious sedation. The standards apply to everyone who is involved in the administration of conscious sedation in dentistry, including dentists, doctors, nurses and dental care professionals. The report is part of the Intercollegiate Advisory Committee for Sedation in Dentistry's aim to improve standards in dentistry and ensure dental patients receive safe, quality care in both the primary and hospital setting.

The report provides best practice guidance around:

- Care pathways - this includes preparation for sedation and consent for treatment
- Clinical sedation techniques - information around the clinical team required for each conscious sedation technique

- Peri-operative care - this includes processes for monitoring, management of any potential adverse events, recovery, discharge and details of required follow-up care

- Patient information - outlines written information required for adult and child patients

- Education and training - this provides details of the appropriate validated education and training and demonstrated competence required that is assessed through a robust process.

Professor Richard Ibbetson, Chair of the Intercollegiate Advisory Committee for Sedation in Dentistry, said:

'These national standards are important for ensuring that as a dental community we are delivering safe, and high quality care to our patients, across the country.

'Administrating conscious sedation delivers many benefits to patients; however, all procedures carry a degree of risk. We need to ensure that all practitioners follow these national standards in their day to day practice so that we deliver safe and high quality care to patients. We hope that these new guidelines will help to improve sedation services in the primary care setting and ultimately relieve the pressure on referrals to secondary care'.

\section{WW1 DENTURES IDENTIFIED BY BDA}

The BDA Museum has assisted a team from the Joint Casualty and Compassionate Centre (JCCC, based at Imjin Barracks, Gloucestershire) with the identification of a set of dentures recovered from World War One. Their aim is to try to identify remains of service personnel from the First and Second World Wars using any personal or regimental artefacts that may have been located. The team will then organise a military burial for the servicemen and invite any known family members.

This upper vulcanite denture (pictured) with porcelain teeth was found in 2013 in Ypres, Belgium. The description stated that the denture was inscribed with the name 'Rauhe'; this prompted JCCC to pose the question, "Could this be the patient, dentist or technician, or some sort of military mark'? At the outbreak of the First World War, civilian dentists' and technicians' skills were in demand to treat the troops to make them dentally fit. Extraction and the fitting of dentures was the usual course of treatment. These dentures were generally not marked by the technician. However, a reference to the marking of wartime dentures was made by Mr A. Taylour of Tolworth Surrey in his description of the first major dental laboratory unit in northern England. The dental section of the RAMC in the Northern Command was started in the early spring of 1916 at The Second Northern General East Leeds War Hospital. ... It was found much better to allow each mechanic to complete a

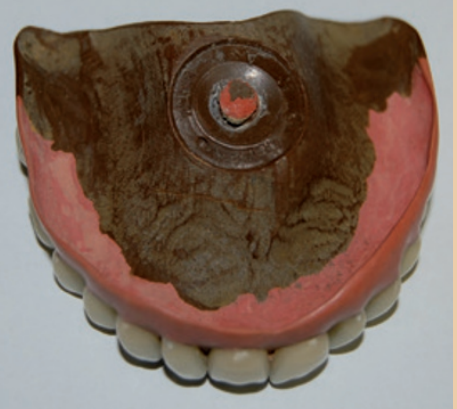

denture from start to finish. A prefix letter referred to the camps in the Northern Command where a dental officer was stationed, eg A Alnwick, S Scotton, R Redcar etc'.

However, on receipt of images of the dentures from JCCC, the markings were found to relate to the suction disc. In 1905, Carl Rauhe of Dusseldorf patented the process of moulding a stud or button into the vulcanite base. His further patent, filed in the USA on 24 October 1911, was for attaching a rubber disk to the stud. His invention was then patented in England, Germany, France, Austria-Hungary and Belgium. The studs and disks were sold by C Ash, Sons and Co Ltd throughout the war. 